\title{
Acute promyelocytic leukemia
}

INSERM

\section{Source}

INSERM. (1999). Orphanet: an online rare disease and orphan drug data base. Acute promyelocytic leukemia. ORPHA:520

Acute promyelocytic leukemia (APL) is an aggressive form of acute myeloid leukemia (AML; see this term), characterized by arrest of leukocyte differentiation at the promyelocyte stage, due to a specific chromosomal translocation $\mathrm{t}(15 ; 17)$ in myeloid cells. APL manifests with easy bruising, hemorrhagic diathesis and fatigue. 